\title{
Feasibility and Acceptability of a Program to Promote Positive Affect, Well-Being and Gender Empowerment in Black Women Living with HIV
}

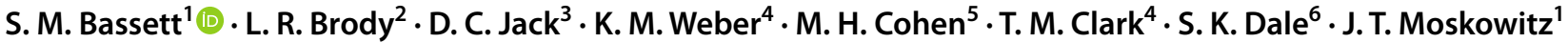

Accepted: 11 November 2020 / Published online: 2 January 2021

(c) Springer Science+Business Media, LLC, part of Springer Nature 2021

\begin{abstract}
While programs and interventions intended to increase positive affect among people living with HIV (PLWH) and other chronic diseases have been associated with improved health outcomes, including decreased depression, programs have not been tailored specifically for Black women. We tailored a program designed to increase positive affect and to decrease depressive symptoms in PLWH to a group format for Black WLWH. We also added skills to increase gender empowerment. We then tested the acceptability and feasibility of this program with 8 Black WLWH. The program was acceptable and relatively feasible, as assessed by women's participation and feedback about program clarity and helpfulness, which women rated above 9 on a 10-point scale. A few women suggested that optimal delivery point for some skills taught would be shortly after HIV diagnosis. A proof-of-concept program intended to bolster positive emotions and gender empowerment and decrease depression can be tailored for Black WLWH and is relatively feasible and acceptable. A randomized controlled trial is needed to assess the preliminary efficacy of this program on positive affect, depression, and other health outcomes for WLWH.
\end{abstract}

Keywords HIV · Women · Positive affect · Gender empowerment · Proof-of-concept

\section{Introduction}

Understanding predictors of optimal psychological and physical health outcomes for people living with human immunodeficiency virus (PLWH) is a critical public health issue. Positive psychological constructs, such as positive affect and spirituality, are associated with better outcomes, including increased engagement in care, increased likelihood

S. M. Bassett

sarahbassett2019@u.northwestern.edu

1 Medical Social Sciences, Northwestern University, Chicago, IL, USA

2 Psychological \& Brain Sciences, Boston University, Boston, MA, USA

3 Fairhaven College of Interdisciplinary Studies, Western Washington University, Bellingham, WA, USA

4 Cook County Health and Hektoen Institute of Medicine, Chicago, IL, USA

5 Department of Medicine, Rush University and Stroger Hospital of Cook County, Chicago, IL, USA

6 Department of Psychology, University of Miami, Coral Gables, FL, USA of viral suppression, and reduced likelihood of mortality [1-4].

Our group has tested multi-component interventions intended to increase positive affect in PLWH or other populations living with health-related stress [5-7]. In a large randomized trial, we tested a positive affect intervention on a mostly male (91.7\%) sample of people recently diagnosed with HIV [5]. The intervention was delivered via one-onone in-person sessions, and included teaching participants skills that targeted positive affect including noticing and capitalizing on positive events [8-10], gratitude [11-13], mindfulness [14], positive reappraisal [15, 16], focusing on personal strengths [17], achieving attainable goals [18, 19], and engaging in altruistic behaviors or acts of kindness [20,21]. At ten months post-intervention, participants in the intervention group reported higher past-day positive affect, reductions in intrusive and avoidant thoughts about HIV, and a lower likelihood of being on antidepressants as compared to the control group [5]. In another randomized trial of the positive affect intervention delivered in-person to men living with HIV (MLWH), the program resulted in durable and clinically meaningful reductions in HIV viral load as well as concomitant improvements in positive affect and reductions in self-reported stimulant use [22]. 
While the multicomponent positive affect intervention has been tested in mixed-gender, mostly male, samples of PLWH in a one-on-one format, it is crucial to tailor interventions intended to increase positive affect for women living with HIV (WLWH), who are an especially vulnerable population. For example, the estimated rate of intimate partner violence among WLWH is 55.3\% [23]. Importantly, WLWH (both cis- and transgender) who report recent trauma have more than four times greater odds of antiretroviral failure, independent of adherence, as compared with women who have not experienced recent trauma [24]. In addition, WLWH are more likely to suffer a lack of economic and educational opportunities and a history of racial and gender discrimination than HIV seronegative women [25-27]. WLWH also tend to engage in self-silencing, or not stating their needs in order to avoid relationship loss or abuse [28]. Self-silencing among WLWH has been associated with higher likelihood of depression [38], a lower likelihood of engaging in safe-sex behavior [29], and a lower likelihood of achieving $\geq 95 \%$ antiretroviral therapy (ART) adherence, especially among women who are racial/ethnic minorities or who have a history of abuse [30]. These multiple risk factors exist within the context of gender and racial inequities, and many researchers have called for interventions that specifically increase gender empowerment among WLWH to improve symptoms of depression, self-care and medication adherence [31].

Gender empowerment skills (asserting and communicating rights, needs and feelings effectively in the face of gender inequities), including the inverse of self-silencing, i.e., selfadvocacy, and a related construct, self-efficacy, have been shown to be beneficial for interacting with the health care system, obtaining and adhering to ART, lowering depression, and effectively engaging in self-care among WLWH [32]. Moreover, positive psychological constructs have been shown to have salubrious effects among WLWH and mixedgender samples of PLWH. Specifically, self-compassion has been associated with lower depressive symptoms in mixedgender samples of PLWH, and self-care has been associated with higher health-related quality of life in WLWH [33, 34]. In addition, positive affect has been associated with an increased likelihood of HIV viral load suppression among WLWH [3]. Research has suggested that loving-kindness meditation, a spiritual practice in which thoughts of compassion toward oneself and others are promoted, may be a useful component of improving health, although it has not yet been included in an intervention targeted for WLWH $[35,36]$.

Depression remains the most common comorbidity for PLWH with rates as high as 34 to $67 \%$ among WLWH [37]. WLWH have higher rates of clinical depression than their uninfected peers, than the general population, and than MLWH $[38,39]$. Elevated depressive symptoms in WLWH are significant risk factors for worse self-care behaviors and heightened sexual risk behaviors [40-42] as well as for treatment non-adherence, virological failure (inability of antiHIV drug treatment to reduce and maintain viral load to less than 200 copies per ml.), and higher mortality rates [43-46].

Issues of gender empowerment and self-advocacy in relation to depression are especially important for Black WLWH, who constitute the majority of WLWH in the U.S., and whose intersecting identities of being female and Black in the context of patriarchy, anti-Blackness, racism, and HIV stigma have direct implications for their health and wellbeing [47]. The theoretical framework of intersectionality [48] emphasizes the importance of multiple systems of oppression which dynamically interact to affect an individual's experience of self, as well as access to resources, functioning, and health [48-50]. Importantly, "self-silencing" for Black women is complicated, because oppression has demanded that Black women remain silent [51, 52]. Even when simply speaking, they can be stereotyped as angry and their views dismissed [53]. Self-advocacy may be interpreted as a threat, requires constant vigilance (e.g., pick your battles, remain calm even when hurtful comments are being thrown at you), and does not guarantee a positive outcome [47]. Black WLWH in the U.S. are less likely to be adherent to ART than other racial groups [54], are less likely to be on an ART regimen even when it is medically indicated [55], and have higher mortality rates 10 years after highly active anti-retroviral therapy initiation than White women (17.3\% for Black women, as opposed to $8.3 \%$ for White women) [56]. In light of these issues, we targeted the intervention to be relevant to the concerns and issues of Black women.

Importantly, a recent meta-analysis of group interventions to improve medication adherence in WLWH concluded that group interventions were more effective than individually delivered treatments [57]. Groups can provide social support, enhance mutuality(in which care for self and others is balanced), and provide peer modeling of skills, all of which have been found to be beneficial for health outcomes in WLWH [32]. In this paper, we report on the development of a group program to enhance positive affect and gender empowerment and decrease depressive symptoms for Black WLWH. We aimed to address the feasibility and acceptability of the program's delivery and content by assessing participation rates as well as eliciting feedback from participants on modifications to improve the program and maximize usefulness for Black WLWH.

\section{Method}

\section{Development}

A multidisciplinary team of investigators with expertise in psychology, medicine/HIV, and public health modified the 
content of a previously tested multi-component positive emotion intervention [5]. The intervention was adapted to be more acceptable and relevant for Black WLWH by adding in skills to enhance gender empowerment including self-assertiveness and the recognition of women's rights in the face of sexism and racism (e.g., the right to say no, the right not to be hurt), to decrease self-silencing, and to improve self-care, including goal-setting and physical activity/exercise, based upon previous research on the needs of WLWH [30]. For example, self-care was taught with reference to an illustration of a hand (i.e., "Self-care is in your hand."), with each of the five fingers labelled with an important component of self-care, including "exercise," "living clean: taking medication and but not doing drugs, engaging in heavy drinking, or smoking," "healthy food and water," "safe and supportive relationships," and "sleep." In the palm of the hand was "self-compassion and forgiveness". Given the low formal education and literacy skills for many WLWH, with $38 \%$ having less than a high school education [58], the intervention was developed for participants with a low formal educational attainment. Concepts and skills were described assuming a less than 9th grade reading level and included many concrete examples and pictorial illustrations.

The treatment was trauma-informed throughout, with the facilitator trained to help participants manage distress if they initiated discussion of previous traumas, to identify trauma-related triggers for stress and anxiety, to teach emotion regulation strategies for dealing with stress related to trauma, to recognize safe and unsafe situations, and to refer participants to outside resources for trauma treatment when indicated. More specifically, the facilitator was trained to listen for painful traumatic experiences and to acknowledge and validate accompanying pain, anxiety, and self-blame. She was also taught to help apply skills being learned such as mindfulness, self-compassion, and self-care to depressive and other symptoms that might result from traumatic memories, and to gently redirect the participant to presentmoment topics and present-moment awareness if the participant seemed disoriented or agitated, following Dialectical Behavior Therapy strategies [47].

Moreover, the intervention content was developed with examples that were relevant for the Black community, including vignettes to exemplify self-silencing and visual depictions of Black women practicing the taught skills throughout workbooks and manuals. A discussion about the benefits and risks of self-silencing and self-advocacy in the face of stigma, interpersonal abuse, and racial microaggressions, along with sample scripts for potential responses in such situations, was included as one of the modules, with an emphasis on being mindful of context and potential consequences, balancing issues of self-worth, racial identity, safety and needed systemic change.
One of the study's co-authors, who was an existing research assistant and staff member at the WIHS Chicago site, who was well known to participants, and is a Black woman (T.C.), facilitated the group, as a meta-analysis of 52 mental health intervention studies indicated a moderately strong preference for a therapist of one's own race or ethnicity, a tendency to perceive therapists of one's own race or ethnicity somewhat more positively than other therapists, and some benefit for client-therapist ethnic matching in treatment outcomes, especially for Black participants [59]. There is also evidence that participants are less likely to drop out of treatment when their therapists are of their own race or ethnicity [60].

The research team followed an iterative process in which we exchanged drafts of program content to modify to be more acceptable and applicable to the problems that Black WLWH might be facing. In addition to content modification, the team transformed the previous positive psychology intervention [5-7] into a group format. We also created workbooks for participants that contained the week's lesson, suggested homework, and provided a woman-specific journal to all participants that would support continued practice at home. This work resulted in a manual that provided a detailed script for each session, weekly homework exercises, and background materials for session leaders [61].

\section{Participants and Procedures}

All participants were enrolled in the Chicago site of the Women's Interagency HIV Study (WIHS), an observational prospective national cohort study of HIV positive and demographically similar HIV-negative women which has been ongoing since 1994. Participants provide psychological and physical health data biannually and may be invited to participate in substudies $[62,63]$. Twenty Black WLWH from the Chicago WIHS site were invited to participate in a focus group to pilot and assess the intervention approach. Criteria for invitation included a history of chronic depressive symptoms as measured by Center for Epidemiologic Studies Depression Scale (CES-D) scores consistently higher than 16 [42], identified Black racial identity, a self-reported history of abuse, and historical willingness to provide feedback and participate in initiatives for WLWH. We focused on a history of depression and abuse because they are higher among WLWH than in the general population and linked to lower adherence and worse health indicators, as discussed above $[23,30]$. We specifically recruited Black women because they account for $60 \%$ of women living with HIV in the United States and face marginalization (e.g. racism, poverty) that exacerbate depressive symptoms [52] and negative outcomes along the HIV treatment cascade [53].

The session facilitator, a Black woman who is a research assistant at the Chicago WIHS site with a master's degree in 
community public health (T.C.), approached 20 women as outlined above via phone to determine interest in participating and preliminary availability for scheduled focus groups. Twelve of twenty (60\%) women reported interest, but after learning the specific schedule, four of these reported scheduling conflicts and time constraints. Eight women (3/4 of those interested) agreed to participate in the focus groups to assess feasibility and acceptability of a women-specific program create to enhance positive affect.

Because investigators were also interested in obtaining feedback about feasibility and acceptability of the group setting adaptation, sessions were delivered to participants in a group, as they would be for an intended future program, and participants were asked to focus on evaluating content, delivery, and format. Participants attended six weekly in-person focus group sessions, each approximately $2 \mathrm{~h}$ in length. The first hour and a half was devoted to presenting specific skills following the adapted manual and the last $1 / 2 \mathrm{~h}$ consisted of the participants providing written and oral feedback about the session's content, format, and delivery during a programprovided lunch.

All program sessions took place in a private conference room. At the end of each session, the facilitator handed out the weekly feedback questionnaires, and women left their completed anonymous questionnaires on the table face down. Participants were reimbursed for transportation costs and received lunch and a $\$ 20$ gift card at each session. Investigators held a weekly phone conference to discuss the previous session and revise subsequent session content, format, and delivery based on this feedback. For example, if it became clear that the next week's session would be too long, investigators would discuss revisions, for example which skill-use examples or exercises might be dropped.

As this study was focused on the development and tailoring of the positive affect program, it was deemed to meet criteria for exempt human subjects research by the respective IRBs involved. As such, we did not link individual demographic or clinical data to participants' feedback regarding feasibility and acceptability or audio or video record sessions. However, the first author (S.B.) sat in on each session and took observer process notes, as detailed below.

\section{Session Content}

See Table 1 for an overview of skills presented, rationale for skill inclusion, and weekly homework. Session 1 began with introducing women to each other as well as generating and discussing group rules and agreements (e.g., be respectful and kind, maintain confidentiality). Sessions $2-6$ began with the facilitator asking whether participants had completed the previous week's homework, and about barriers and facilitators to completion. The facilitator then led the group in "three breaths of arrival," a very short mindfulness practice (one of the positive psychology skills) in which participants focused on their breath as they inhaled and exhaled three times, prior to learning new skill content. For all sessions, the facilitator followed this format of the brief mindfulness practice, then presented new skills to women as detailed in Table 1 and helped them plan for ways they could practice the skill in the coming week. The week's homework was introduced at the end of the session.

Preceding each session, the facilitator received weekly two-hour trainings in administering the upcoming session under the primary supervision of two psychologists with extensive clinical expertise (L.B. and D.J.). A health psychology researcher (S.B.) sat in on and observed sessions, including the feedback session, and took process notes. The process notes addressed how participants responded to facilitator questions and prompts, how long each skill took to teach, and when participants appeared engaged or disengaged with the material.

\section{Feedback Sessions}

At the end of each session, participants completed Likert scales [1-10] for each of the skills presented that day, rating each skill for clarity of presentation, perceived helpfulness for WLWH, perceived likely motivation of WLHW to use the skills, likely fit with spiritual beliefs and practices of WLHW, and perceived helpfulness of homework to WLWH. In addition, one week following completion of the 6 weekly focus groups, there was an additional 2-h feedback session to evaluate overall and session-specific program content, format, and delivery. During this dedicated feedback session, which four women attended and for which a fifth woman provided written feedback asynchronously, women were each asked to provide written feedback to a subset of several open-ended questions regarding feasibility and acceptability of the program delivery and content. Sample items included, "What was your favorite skill?" "How much would you recommend to other WLWH that they participate in this program? Why did you select that rating?" "How could the group be improved for women living with HIV?" and "How do you think the program skills fit in with the spiritual beliefs or practices of women living with HIV?" We asked each woman to write answers to only $1 / 2$ of the questions in order to keep the length of the questionnaire manageable and in order to obtain sufficient detail in women's responses, with every other woman doing the first $1 / 2$ and every other woman doing second $1 / 2$ of the question booklet so that those sitting next to each other were completing different questions. Participants were then asked to share their individual feedback in the group setting facilitated by a co-author (K.W.) who was not directly involved with program facilitation. During the feedback session, women often referred to their own experiences attending the group in addition to 


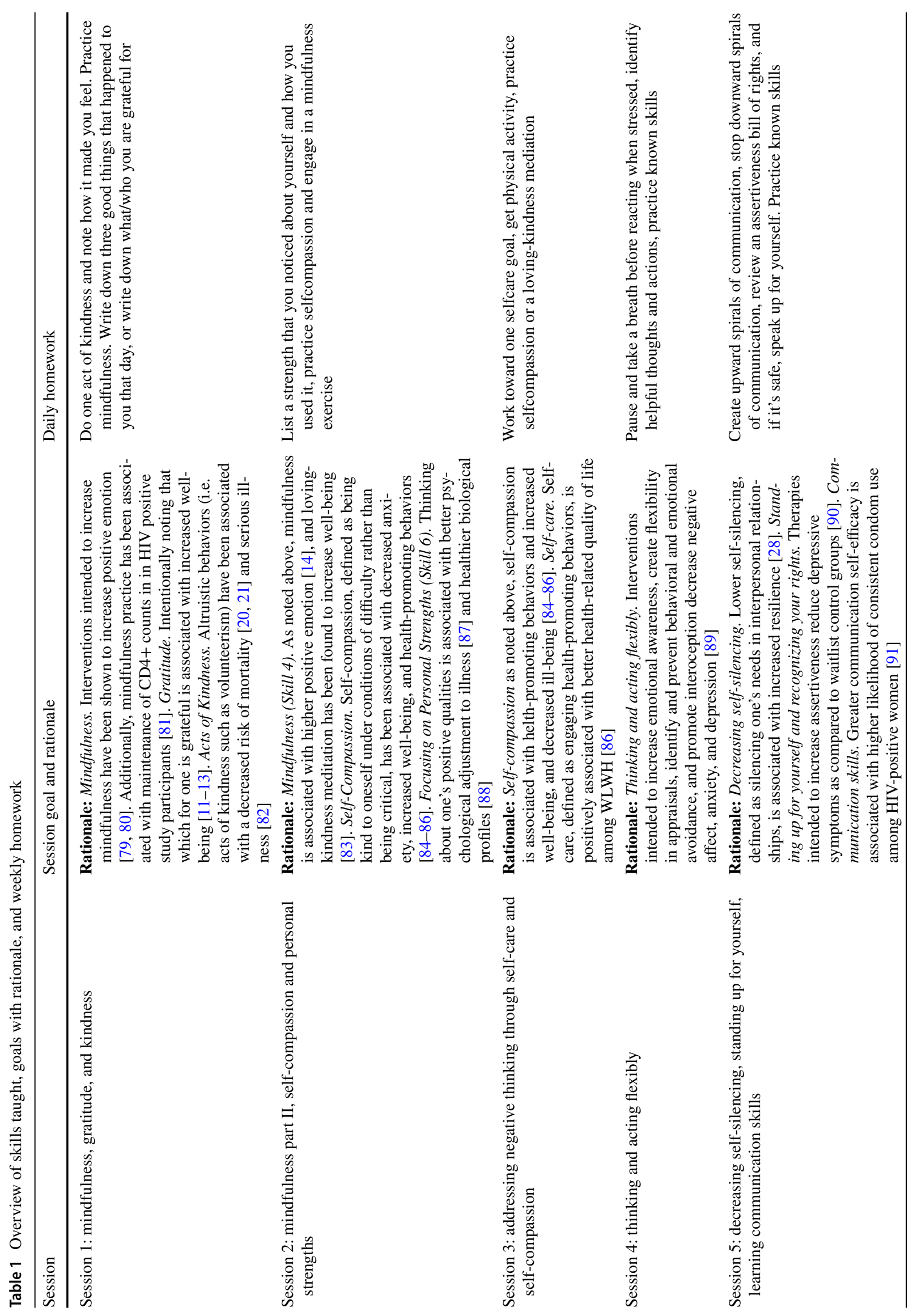




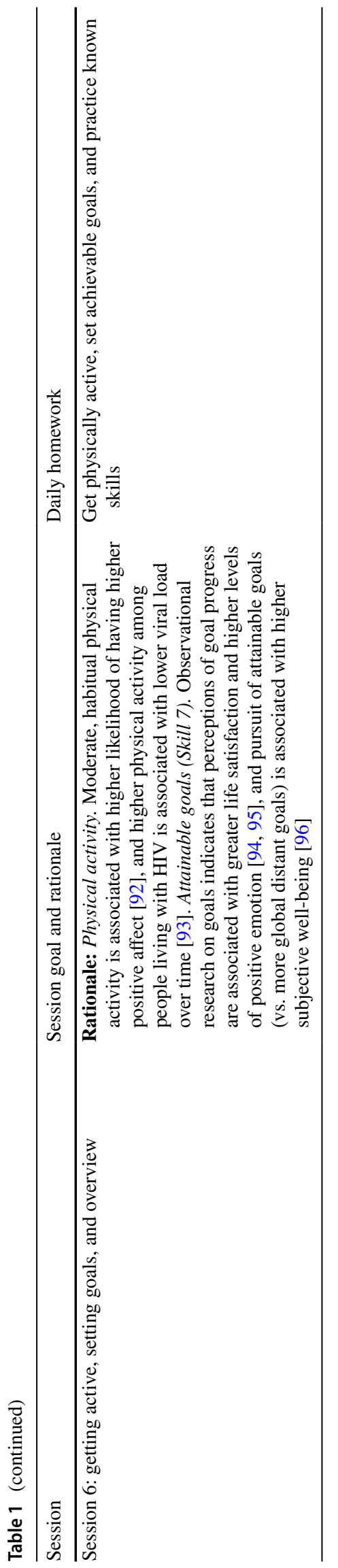

reflecting on the appropriateness of the group for WLWH in general. Women had the opportunity to provide oral feedback on the appropriateness of session length, whether this program would be better in a group or individual format, when this program would be most useful in relation to HIV diagnosis, which skills would be useful proximal to HIV diagnosis, which skills were useful to women regardless of time since diagnosis, and whether this program should be peer-led.

\section{Feasibility and Acceptability}

\section{Feasibility}

We assessed feasibility via the number of women who agreed to participate and attend the first session, the number of participants who actually attended each session, as well as any stated reasons for non-participation during the course of the weekly sessions.

\section{Acceptability}

We assessed acceptability of individual sessions on a weekly basis and at the final feedback session, using rating scales and open-ended questions described above.

\section{Results}

\section{Feasibility of Development}

Working with a multidisciplinary team of researchers, it was feasible to customize this program for a small proof-of-concept program with WLWH who had a history of abuse and ongoing high chronic depressive symptom burden.

\section{Feasibility and Acceptability of Delivery}

We had approached 20 women with the hope of recruiting 12. Although 12 expressed interest in the study, only eight women formally enrolled, with the other four reporting scheduling conflicts and time constraints. One woman who initially agreed to participate did not attend any sessions. Thus, seven women attended the first session. Prior to each session, the facilitator contacted each participant to remind her of the upcoming session. Women who could not attend most often reported scheduling conflicts or transportation difficulties even though the study reimbursed for public transport. Of the seven women who were enrolled in the group, three women attended all six sessions; two women attended five of six sessions, one woman attended four of six sessions, and one woman attended only the first session. 


\section{Feasibility and Acceptability of Content}

\section{Weekly Feedback}

Participants' weekly feedback ratings indicated a highly acceptable program with regard to clarity of skill presentation, perceived helpfulness of each skill to WLWH, perceived likely motivation of WLWH to use the skills, fit with spiritual beliefs and practices of WLWH, and helpfulness of homework to other WLWH. On a 1-10 scale, women's range of scores across all skills was $9.43-10$ for clarity, 9.60-10 for helpfulness, $9.67-10$ for motivation to use the skills, 9.33-10 for fit with spiritual beliefs, and 9.83-10 for helpfulness of homework.

\section{Qualitative Analysis of Women's Feedback and Observational Notes}

Women's written and verbal comments were analyzed using a thematic qualitative analysis, in which similar responses were grouped together as a theme, as identified by first author (S.B.) in collaboration with co-authors. During the final group discussion, participants' oral feedback was visually documented on a group bulletin board so that key themes could be highlighted and also integrated with the final focus group rating scales. Women's responses were assumed to be their realistic appraisals of the program contents and format, as consistent with a realist approach to qualitative data analysis as discussed by Maxwell and Miller [64]. In addition to analyzing women's written and verbal comments, the first author (S.B.) attended all sessions as an observer and took notes on attendance, on the topics on which women seemed engaged or distracted, and timed how long each skill took to present. These observational notes were used as additional descriptive data to supplement the thematic analysis [64]. Themes identified included the importance of emphasizing the following skills: self-care, goal setting, communication and self-advocacy skills, mindfulness, and spirituality. Other identified themes included the importance and challenges of a group format, using food and drink to build group cohesion, addressing women's traumatic and stressful experiences, the length of time involved in sessions and learning skills, and the usefulness of the program in relation to time since HIV diagnosis.

Self-care When the group was discussing self-care in the feedback session, one participant stated, "That self-care is like the golden part for me." Self-care was especially important for the women in the context of being caretakers, as all of the women had children and/or grandchildren. One participant thought for a minute, and noted, "If you're a caretaker with HIV, you're taking care of everybody else, but nobody is taking care of you," and that "We need to be able to take care of us." These quotes are consistent with research on self-silencing, in which prioritizing care for others may interfere with self-care [65-67]. One participant told the group that her doctor was encouraging her to engage in selfcare and indicated that information that participants learned in the program aligned with and supported her doctor's recommendations. Participants kept coming back to the selfcare session and saying that self-care was crucial. They agreed that mindful breathing was a component of self-care, and group members at the feedback session all said that they were using three breaths of arrival in their daily lives and truly enjoying this skill.

Goal Setting and Related Skills During the feedback session, women suggested that setting goals would be very helpful for dealing with denial and confusion surrounding diagnosis of HIV and living with the virus. One participant gave an example of how setting goals was important for in managing her HIV care. She was having trouble with her health and set the attainable goal of seeing her doctor. She set two more goals for what she wanted to accomplish within her appointment that included remembering what she is entitled to as a person and using active communication skills to facilitate better patient-provider interactions. Similarly, during the feedback session, one woman indicated that she had just filled her prescription for antiretroviral medication. She said that goal setting, self-care, loving-kindness, and mindfulness were the skills that helped her get to the point that she could accomplish this.

Communication and Self-advocacy Skills Communication skills were a central theme during the feedback session. In particular, women noted the need for a better ability to communicate with healthcare providers so that they could more easily navigate medication adherence, HIV disclosure and relationship negotiation. During the discussion about communication, one woman stepped out of the room to contact her healthcare provider in order to express her strong desire for a more thorough workup of her ongoing acute symptoms (pain) and conveyed to the group that for the first time in many years, she had decided to take her HIV medications. She reported that the decisions to contact her healthcare provider and to take her HIV medications were direct results of the program content and skills learned. Other women noted that many of these skills learned could be used to improve patient/provider interactions and that it would be useful to incorporate this content more explicitly.

Mindfulness In the context of a discussion about the helpfulness of mindfulness, one member gave an example of how she was using mindfulness: "When you're in a situation, just breathe. When you're getting into a situation where you're losing your self-care, being able to stop, 
breathe, and reset is critical for you to get to self-care." However, mindfulness practice was not a universally positive experience. During a session that taught mindfulness, sitting still invoked a flood of traumatic memories for one participant, who broke into tears. Here the facilitator used trauma-informed treatment, validating the participant's feelings, redirecting her to use self-care and self-compassion skills, and giving herself permission to redirect her attention to her surroundings rather than focusing on her breath.

Trauma History Importantly, many women in the group were coping with multiple traumas, including recent spousal loss and domestic violence, which they shared with other group members. The trauma-informed group structure provided an opportunity for women to process stressors and get peer support and guidance in how to cope. The facilitator attempted to apply the weekly skills being taught to ongoing stressful or traumatic issues that were raised, especially the importance of self-care and self-advocacy. However, because the goal of the group was to teach skills and to evaluate program content, format, and delivery, the facilitator had to balance supporting women while also limiting the discussion of individual traumas, which could be challenging.

Importance of the Group Format Women appeared to want connection with other WLWH, especially with regard to practicing using the skills. Women also seemed to draw solace from speaking with other women about the problems that they were going through. Throughout sessions, women said that they hadn't previously known how good their lives were and coming to this group made them realize that they had a lot to be grateful for. When asked if it would be better for women to learn the skills as a group or individually, women explained that it was helpful to learn from other women in the group. They thought the group process was good for understanding the skills in the context of their own lives and helped them to feel gratitude for where they are in their lives. They also expressed appreciation for the group as an environment to practice skills. Some women disclosed that they would like to read out loud in front of other women in order to improve their literacy skills in a safe space.

Women also talked about how they were "learning something here" in multiple sessions. They reportedly told their friends that they had to go to class or school when they were talking about the program. The concept of continued education seemed especially important to participants as they all valued education highly. In the final feedback session, one participant said that she liked this group much more than groups wherein participants just provide information via diaries, etc., because she felt as though she was learning something. She stated, "This is a good group because it's a learning group. This group was to teach skills and to learn skills, which was important."

When asked if this group should be peer-led, several participants gave a resounding no, one shook her head vigorously against the idea, and one participant noted that it would be difficult for another WLWH to lead the group, saying, "It would be touchy to have someone switch from peer to staff and back." Participants explained that they want to have this group led by someone with content expertise and who can keep them on task with respect to learning new skills.

\section{Challenges of Group Dynamics}

The use of electronic devices during the group sessions was a contentious topic of discussion during the feedback session. While some women stated that they did not feel as though they could be away from their phones because they wanted their children to be able to contact them, other women felt that the use of smart phones significantly detracted from the positive group dynamics. As we mentioned above, focusing on phones may become a way of avoiding distress, including avoiding connection and conflict with other group members. Further, late arrivals and early departures posed a challenge for building group cohesiveness and trust. Finally, there were also differences among women regarding how much individuals spoke during sessions, with some women talking at length, and some not sharing enough.

Women had specific feedback about how to improve group dynamics. One potential solution discussed by participants was to have a basket in the room in which participants and facilitators could put their phones. Most women reacted positively to this idea, while one reacted less enthusiastically. They also reiterated the importance of group rules as crucial to the success of the group approach. For example, they liked the idea of having a rule about time limitations for talking (perhaps even using a visible timer) and a reminder to be given about this every week. They also suggested that a facilitator could write "off subject" on a whiteboard, and point to it as a gentle reminder when necessary if subject matter was not relevant. Women wanted the time within the program to be more focused on the skills that they were there to learn, with less time dedicated to having women talk or reflect so that the facilitator could more easily get through all intended material.

\section{Food and Drink as a Way to Foster Group Cohesion}

At the start of each session, women either asked for coffee or tea, or we offered it to them. This allowed participants to ease into the program content and also allowed time for community building. One benefit of this soft start was that women who were arriving late missed less session material 
than they would have if the program started precisely on time. In addition to receiving beverages at the start of each session, some women stated that they appreciated sharing a provided lunch after their 2-h weekly sessions. However, one woman noted that the actual quality of the food was her least favorite part of the program. As food insecurity often accompanies the economic vulnerability of WLWH, providing food was valued by participants.

\section{Length of Sessions}

When queried about session length, three participants stated that it would be helpful to have less content per session and longer sessions. They stated that $2 \mathrm{~h}$ of materials would be better than one and a half hours. One participant disagreed and stated that she was pressed for time as it was in this program. At least two women indicated that they would prefer to keep sessions at $1.5 \mathrm{~h}$ and have these occur over four rather than 6 weeks but provided the option for two courses that build on each other, one more introductory and another for a more intermediate level. In this tiered approach, entry level groups would meet for a shorter amount of time per session and for fewer weeks than intermediate groups. This would provide an opportunity for women to progress at skill development at varied paces. Thus, feedback about length of sessions varied among participants.

\section{Timing of Learning the Skills in Relation to HIV Diagnosis}

When discussing optimal timing of learning program skills in relation to HIV diagnosis, there was discussion that an HIV diagnosis today is very different than an HIV diagnosis in the late 1990s or early 2000s. The majority of the participants were more than 10 years post-HIV diagnosis. Some women noted that specific aspects of the program would have been especially helpful if these were taught more proximal to HIV diagnosis, which may have helped them to cope with the stigma accompanying HIV [68, 69]. Specifically related to the potential utility of the program with regard to post-diagnosis stigma, one participant stated, "A lot of it comes back to how you got this disease, who you went to share it with. Staying positive with the disease can be a roller coaster." Similarly, when asked at what point in life a program like this would be most useful, one woman noted, "My struggle would have been easier if I'd learned this stuff earlier on." Another stated, "Had I had something like this when I first diagnosed, I think I'd be further in life. I couldn't find a group that would actually help me grow." However, they said that the current group and skills were still of great use to them at this time in their journeys of living with HIV.

When queried regarding which skills would have been useful if they had been taught earlier on in relation to HIV diagnosis, participants stated that specific skills would have been useful for different reasons. Women stated that physical activity/exercise and goal setting would have been very useful in helping in coping with HIV diagnosis. They stated that stress management and mindfulness, especially with relation to mindful eating, would have been useful, and that enhanced communication skills would have informed how they disclosed their HIV status with family and partners, and would also have helped them navigate romantic relationships with greater ease. Participants also stated that self-care would have been very useful close to diagnosis, with one participant noting that after HIV diagnosis, "You get up every morning and you're like, 'Why would I take a shower?" Participants agreed that if they had learned how to achieve greater levels of self-care earlier in relation to diagnosis, they would have had struggled less and likely had better health. With regard to remembering your rights and how to communicate effectively, one woman stated, "If you haven't been exposed to these skills, you might be missing out on a lot-especially when you're first diagnosed".

\section{Spirituality}

During the feedback session, participants were asked whether it would make sense to include spirituality in a program like this one. Most women indicated that spirituality was a strong aspect of their lives even previous to their HIV diagnosis, so it was not a new skill but rather something they heavily depended on for coping with HIV. Some women indicated that their spiritual practices had evolved since their HIV diagnosis and that for some, spirituality, or the belief in something bigger, was a turning point for "getting clean." Participants suggested that incorporating spirituality as a strength that WLWH can draw upon would be useful.

\section{Discussion}

The current program demonstrates that a positive skills learning skills intervention originally developed primarily for MLWH $[5,70]$ can be adapted in a group format for Black WLWH and tailored to be relevant for women with a trauma history, depressive symptoms, and those with low educational attainment. The adapted intervention was also demonstrated to be relatively feasible and acceptable. Focus group participants enjoyed learning the skills, felt as though they were helpful, and felt as though other WLWH would find the skills useful. The intervention is worth developing further to identify and test the most useful content and delivery format. 


\section{Lessons Learned}

We learned five primary lessons about developing a positive psychology intervention for WLWH from the current study: (1) increase feasibility by offsetting barriers that may prevent participants from attending groups consistently (e.g., by offering internet-based groups). (2) capitalize upon the potential of the group setting to emphasize and encourage social supports, peer modeling, and mutuality, which may decrease depression and enhance effectiveness in learning skills. (3) practice positive psychology and gender empowerment skills in session to decrease avoidance and manage the distress evoked by sharing and listening to traumatic experiences. (4) place more emphasis on specific intervention skills, including effective communication with doctors, self-care, goal setting, and mindfulness, and integrate these with women's ongoing spiritual practices. (5) consider the time since HIV diagnosis and utility of interventions, given participants' suggestions that some of these skills would have been useful more proximal to HIV diagnosis. Each of these lessons bears further discussion.

Given that only four to six women attended each session, researchers need to facilitate greater feasibility of attendance in the future. Maintaining consistent attendance in groups was more difficult than we had anticipated due to issues surrounding housing and economic insecurity, transportation difficulties, and scheduling conflicts. However, our recruitment and retention rates were consistent with a previous review of studies evaluating attendance at substance abuse and psychiatric treatment programs, which reported that between $10 \%$ and $60 \%$ of scheduled appointments are not attended [71]. In order to make this intervention more feasible, researchers may find it useful to offer internet-based group meetings for women who have access to technology, offer more than one session per week so that women have the option of choosing a time best for their schedule, or provide some additional online materials that women can learn from when they do miss a session. Having online groups or materials would be especially useful when public health issues (e.g., the COVID-19 pandemic) prevent meeting safely in person.

Second, we learned that women found the group especially important as a setting to enhance social supports, peer modeling, and mutuality. The group provided a safe space in which to learn skills, share personal stories, and gain support, consistent with other work demonstrating increased social support among WLWH in a group intervention [46]. The safe space provided by the group is exemplified by the facts that some women wanted to read out loud in front of their peers to improve their literacy skills, exchanged phone numbers so that they could have the opportunity to meet and talk outside of the group setting, and reported that eating together was one of the group highlights. Given that $35 \%$ of
WLWH in a longitudinal study reported some degree of food insecurity [72], mindfully eating lunch together as a group could be a beneficial component of the program, providing opportunities for nutrition, but also opportunities for community building and socializing. Adding group components such as walking together or engaging in yoga or meditation might also be helpful.

Third, we learned that applying positive psychology and gender empowerment skills to help manage distress evoked by sharing or listening to traumatic events was critical for maximizing participants' growth, engagement and learning in the moment. Researchers should incorporate more material on how to apply self-compassion, self-advocacy, and mindfulness to the distress evoked by sharing traumatic stories and listening to others' trauma. Allowing women to share their stories and to manage distress using learned skills is potentially of great benefit. It is also critical to support group members' distress management skills when listening to traumatic experiences so that they can be witnesses and provide validation. The women's concrete suggestions for decreasing avoidance and distractions, including providing a basket for all phones to be placed so that women can be fully present throughout the sessions, muting phones, or providing gentle reminders about rules, might be one step in achieving these goals.

The fourth lesson highlights placing a greater emphasis on skills which previous research has found to be important in the treatment of depression, including self-care, goal setting, and mindfulness. Previous research has indicated that self-care in WLWH is critical for improving and maintaining health [34], and the results of the current study suggest that learning how to communicate with medical providers is a self-care skill that WLWH find useful. Learning effective communication skills for interacting with the medical profession may be especially important for the Black community, given the historical betrayals and mistreatment by the medical community and ensuing levels of mistrust [73]. Further, emphasizing connections between ongoing spiritual practices and positive psychology skills may also be especially helpful for Black women, given the importance of spirituality in the Black community [74]. One study has shown that among Black women who have experienced domestic violence, those with higher levels of spirituality and greater religious involvement reported fewer depressive symptoms [25]. Furthermore, spirituality has been found to be related to a greater sense of well-being, life satisfaction, and mental health outcomes in Latino and Black communities [75]. In a longitudinal study of PLWH (36\% female and 38\% Black), participants who reported an increase in spirituality/religiosity after the HIV diagnosis had slower disease progression, showed significantly greater preservation of CD4 cells over a 4-year period, and had significantly better controlled HIV viral load [76]. 
Finally, we have to consider the time since HIV diagnosis in relation to the effectiveness of interventions. The initial period following an HIV diagnosis is normatively stressful and even traumatic, and can include feelings such as shock, guilt, depression, and fear [77]. Women in this time period may experience stigmatization due to illness, which can compound their feelings of discrimination and isolation $[68,69]$. Individually, women can also be uninformed about the disease and what self-care entails. Group interventions during this time may be especially important. It is possible that the consistently higher levels of depression seen in WLWH many years post diagnosis could be lowered if they were addressed earlier on in the disease. Of course, women who have been living with HIV for many years may also need continued support and reminders about self-care, mindfulness, and goal setting. Further research on how the effectiveness of the intervention and of each of the skills relates to the timing of HIV diagnosis is essential.

\section{Future Research}

Future research should test whether and how this program is beneficial to mental and physical health outcomes, including depressive symptoms, quality of life, self-care, medication adherence and decreased self-silencing, in Black WLWH. Although this small proof-of-concept program showed relatively high feasibility and acceptability in that these women believed that it would be highly useful for other Black WLWH, this must be tested in a larger samples. This program could also potentially be adapted for non-Black women. Additional research should be conducted to investigate feasibility and acceptability with other groups, as the current study's findings are applicable only to Black women living with HIV.

Varying the structure and length for the presentation of each skill should also be further examined. For example, one possibility for the format includes having a short introduction to the skills online or in weekly hour-long sessions, followed by a longer group program for those who are interested. This would respond to some women's suggestion to have more time together and fewer skills covered in each session. A format that combines an individualized online version followed by a group therapy format might also allow women to initially work at their own pace, learn the skills without distraction, and potentially benefit from the social support and mutuality involved in a group. However, given low education and literacy skills for many WLWH [47], an online individualized version may not be appropriate for everyone, and more work should be done evaluating whether the program is helpful for women at all levels of educational attainment.

\section{Limitations}

A limitation of the study is that there were no pre-set criteria as to what rates of participation and attendance we would use to deem the program feasible, and this should be addressed in future research.

Additionally, our assessment of program feasibility and acceptability was based on a very small and highly motivated sample with chronic depressive symptoms who were recruited based on their historical willingness to participate in WIHS activities. They may not be a representative sample of Black WLWH in the US. A further limitation of the study is that we did not ask participants whether race of the facilitator was important to them. It would be helpful to do further research to investigate whether this was true in this case, as has been demonstrated in previous research [59]. It is also a potential limitation that we asked women if this program might be beneficial for WLWH in general (rather than for themselves) on the structured feedback scales. Women's responses to this question may entail drawing on a combination of their own experiences; their familiarity with the experiences of peers living with HIV; or their general ideas about WLWH. There is some evidence to support the assumption that people project their own feelings onto general others with whom they identify [78]. Assuming this is true, it highlights the issues of generalizability of our findings to non-Black WLWH. In the future, adapting this intervention for non-Black WLWH should entail asking a larger and more racially diverse sample of WLWH for feedback about the intervention to potentially replicate and expand our findings. However, it is important to note that often, White (nonminority) women are asked to reflect on the fit of an intervention for all women and their perspectives are viewed as global, rather than as individual perspectives constrained by their lived experiences. Because Black WLWH represent the largest proportion of women with HIV nationally and globally, their perspective on fit is especially needed for interventions for WLWH, whether stemming from their lived experiences or from a more global and general perspective.

Other limitations of the current study are that social desirability may have influenced ratings and open-ended feedback, because the facilitator who led the group (T.C.) was also the person who handed out weekly self-report feedback questionnaires. Although these questionnaires were anonymous and individual women could not be identified, in the future, the facilitator should not be present when questionnaires are being handed out or feedback is being given. Our final questionnaires were relatively long, and some questions required a higher reading level than some women had achieved which limited our ability to get complete answers from all participants. 


\section{Conclusions}

A proof-of-concept program to bolster positive emotion and gender empowerment as a way of reducing depressive symptoms can be tailored for Black WLWH and is relatively feasible and acceptable. Future researchers should replicate results with larger numbers of women and investigate whether adapting program content in ways consistent with the lessons learned from our analysis is helpful in reducing depressive symptoms pre and post intervention. With continued research with larger samples of Black WLWH, mechanisms regarding whether, how, and why positive affect regulation programs are helpful to women can be elucidated, and women can learn skills that may help them achieve better health.

Funding Funding was supported by Third Coast Center for AIDS Research (Grant No. P30 AI117943).

\section{References}

1. Moskowitz JT. Positive affect predicts lower risk of AIDS mortality. Psychosom Med. 2003;65(4):620-6.

2. Carrico AW, Ironson G, Antoni MH, Lechner SC, Durán RE, Kumar M, et al. A path model of the effects of spirituality on depressive symptoms and 24-hurinary-free cortisol in HIV-positive persons. J Psychosom Res. 2006;61(1):51-8.

3. Wilson TE, Weedon J, Cohen MH, Golub ET, Milam J, Young MA, et al. Positive affect and its association with viral control among women with HIV infection. Health Psychol. 2017;36(1):91-100.

4. Ironson GH, Solomon GF, Balbin EG, Ocleirigh C, George A, Kumar M, et al. The Ironson-Woods Spirituality/Religiousness Index is associated with long survival, health behaviors, less distress, and low cortisol in people with HIV/AIDS. Ann Behav Med. 2002;24(1):34-48.

5. Moskowitz JT, Carrico AW, Duncan LG, Cohn MA, Cheung EO, Batchelder A, et al. Randomized controlled trial of a positive affect intervention for people newly diagnosed with HIV. J Consult Clin Psychol. 2017;85(5):409.

6. Dowling GA, Merrilees J, Mastick J, Chang VY, Hubbard E, Moskowitz JT. Life enhancing activities for family caregivers of people with frontotemporal dementia. Alzheimer Dis Assoc Disord. $2014 ; 28(2): 175-81$.

7. Carrico AW, Gómez W, Siever MD, Discepola MV, Dilworth SE, Moskowitz JT. Pilot randomized controlled trial of an integrative intervention with methamphetamine-using men who have sex with men. Arch Sex Behav. 2015;44(7):1861-7.

8. Murrell SA, Norris FH. Resources, life events, and changes in positive affect and depression in older adults. Am J Community Psychol. 1984;12(4):445-64.

9. Zautra AJ, Reich JW. Life events and perceptions of life quality: developments in a two? factor approach. J Community Psychol. 1983;11(2):121-32.

10. Langston CA. Capitalizing on and coping with daily-life events: expressive responses to positive events. J Pers Soc Psychol. 1994;67(6):1112.
11. Emmons RA. Thanks!: How the new science of gratitude can make you happier: Houghton Mifflin Harcourt; 2007.

12. Emmons RA, McCullough ME. Counting blessings versus burdens: an experimental investigation of gratitude and subjective well-being in daily life. J Pers Soc Psychol. 2003;84(2):377.

13. Kashdan TB, Uswatte G, Julian T. Gratitude and hedonic and eudaimonic well-being in Vietnam war veterans. Behav Res Ther. 2006;44(2):177-99.

14. Brown KW, Ryan RM. The benefits of being present: mindfulness and its role in psychological well-being. J Pers Soc Psychol. 2003;84(4):822.

15. Folkman S. Positive psychological states and coping with severe stress. Soc Sci Med. 1997;45(8):1207-21.

16. Sears SR, Stanton AL, Danoff-Burg S. The yellow brick road and the emerald city: benefit finding, positive reappraisal coping and posttraumatic growth in women with early-stage breast cancer. Health Psychol. 2003;22(5):487.

17. Lazarus RS, Folkman S. Stress, appraisal, and coping. New York: Springer Publishing Company; 1984.

18. Carver CS, Scheier MF. Origins and functions of positive and negative affect: a control-process view. Psychol Rev. 1990;97(1):19.

19. Lent RW, Singley D, Sheu HB, Gainor KA, Brenner BR, Treistman $\mathrm{D}$, et al. Social cognitive predictors of domain and life satisfaction: Exploring the theoretical precursors of subjective well-being. J Counsel Psychol. 2005;52(3):429.

20. Musick MA, Wilson J. Volunteering and depression: the role of psychological and social resources in different age groups. Soc Sci Med. 2003;56(2):259-69.

21. Oman D, Thoresen CE, McMahon K. Volunteerism and mortality among the community-dwelling elderly. J Health Psychol. 1999;4(3):301-16.

22. Carrico AW, Neilands TB, Dilworth SE, Evans JL, Gómez W, Jain JP, et al. Randomized controlled trial of a positive affect intervention to reduce HIV viral load among sexual minority men who use methamphetamine. J Int AIDS Soc. 2019;22(12):e25436.

23. Machtinger EL, Wilson T, Haberer JE, Weiss DS. Psychological trauma and PTSD in HIV-positive women: a meta-analysis. AIDS Behav. 2012;16(8):2091-100.

24. Machtinger E, Haberer J, Wilson T, Weiss D. Recent trauma is associated with antiretroviral failure and HIV transmission risk behavior among HIV-positive women and female-identified transgenders. AIDS Behav. 2012;16(8):2160-70.

25. Cohen M, Deamant C, Barkan S, Richardson J, Young M, Holman $\mathrm{S}$, et al. Domestic violence and childhood sexual abuse in HIVinfected women and women at risk for HIV. Am J Public Health. 2000;90(4):560.

26. Markowitz SM, O’Cleirigh C, Hendriksen ES, Bullis JR, Stein M, Safren SA. Childhood sexual abuse and health risk behaviors in patients with HIV and a history of injection drug use. AIDS Behav. 2011;15(7):1554-60.

27. Kelso GA, Cohen MH, Weber KM, Dale SK, Cruise RC, Brody LR. Critical consciousness, racial and gender discrimination, and HIV disease markers in African American women with HIV. AIDS Behav. 2014;18(7):1237-46.

28. Dale SK, Cohen MH, Kelso GA, Cruise RC, Weber KM, Watson C, et al. Resilience among women with HIV: impact of silencing the self and socioeconomic factors. Sex roles. 2014;70(5-6):221-31.

29. Jacobs RJ, Thomlison B. Self-silencing and age as risk factors for sexually acquired HIV in midlife and older women. J Aging Health. 2009;21(1):102-28.

30. Bruck-Segal D, Schwartz RM, Cohen MH, Weber KM, BurkeMiller JK, Kassaye S, et al. The costs of silencing the self and divided self in the context of physical abuse, racial/ethnic identity, and medication adherence in women living with HIV. Sex Roles. 2019;86:716-30. 
31. Pu H, Hernandez T, Sadeghi J, Cervia JS. Systematic review of cognitive behavior therapy to improve mental health of women living with HIV. J Invest Med. 2019;68:30-6.

32. Brody LR, Jack DC, Bruck-Segal DL, Ruffing EG, Firpo-Perretti YM, Dale SK, et al. Life lessons from women with HIV: mutuality, self-awareness, and self-efficacy. AIDS Patient Care STDs. 2016;30(6):261-73.

33. Eller L, Rivero-Mendez M, Voss J, Chen W, Chaiphibalsarisdi P, Iipinge S, et al. Depressive symptoms, self-esteem, HIV symptom management self-efficacy and self-compassion in people living with HIV. AIDS Care. 2014;26(7):795-803.

34. Gielen AC, McDonnell K, Wu AW, O'Campo P, Faden R. Quality of life among women living with HIV: the importance violence, social support, and self care behaviors. Soc Sci Med. 2001;52(2):315-22.

35. Kemper KJ, Powell D, Helms CC, Kim-Shapiro DB. Lovingkindness meditation's effects on nitric oxide and perceived wellbeing: a pilot study in experienced and inexperienced meditators. Explore. 2015;11(1):32-9.

36. Teixeira ME. Meditation as an intervention for chronic pain: an integrative review. Holist Nurs Pract. 2008;22(4):225-34.

37. Cook JA, Cohen MH, Burke J, Grey D, Anastos K, Kirstein L, et al. Effects of depressive symptoms and mental health quality of life on use of highly active antiretroviral therapy among HIV-seropositive women. J Acquir Immun Defic Syndr. 2002;30(4):401-9.

38. Cook JA, Burke-Miller JK, Steigman PJ, Schwartz RM, Hessol NA, Milam J, et al. Prevalence, comorbidity, and correlates of psychiatric and substance use disorders and associations with HIV risk behaviors in a multisite cohort of women living with HIV. AIDS Behav. 2018;22(10):3141-54.

39. Nanni MG, Caruso R, Mitchell AJ, Meggiolaro E, Grassi L. Depression in HIV infected patients: a review. Curr Psychiatry Rep. 2015;17(1):530.

40. Cook J, Grey D, Burke-Miller J, Cohen M, Anastos K, Gandhi $\mathrm{M}$, et al. Effects of treated and untreated depressive symptoms on highly active antiretroviral therapy use in a US multi-site cohort of HIV-positive women. AIDS care. 2006;18(2):93-100.

41. Mota NP, Cox BJ, Katz LY, Sareen J. Relationship between mental disorders/suicidality and three sexual behaviors: results from the National Comorbidity Survey Replication. Arch Sex Behav. 2010;39(3):724-34.

42. Foley JD, Vanable PA, Brown LK, Carey MP, DiClemente RJ, Romer D, et al. Depressive symptoms as a longitudinal predictor of sexual risk behaviors among African-American adolescents. Health Psychol. 2019;38(11):1001.

43. Mayston R, Kinyanda E, Chishinga N, Prince M, Patel V. Mental disorder and the outcome of HIV/AIDS in low-income and middle-income countries: a systematic review. AIDS. 2012;26:S117-35.

44. Carrico AW, Bangsberg DR, Weiser SD, Chartier M, Dilworth SE, Riley ED. Psychiatric correlates of HAART utilization and viral load among HIV-positive impoverished persons. AIDS (Lond, Engl). 2011;25(8):1113.

45. Jallow A, Ljunggren G, Wändell P, Wahlström L, Carlsson AC. $\mathrm{HIV}$-infection and psychiatric illnesses-a double edged sword that threatens the vision of a contained epidemic: the Greater Stockholm HIV Cohort Study. J Infect. 2017;74(1):22-8.

46. Mills JC, Pence BW, Edmonds A, Adedimeji A, Schwartz RM, Kassaye $\mathrm{S}$, et al. The impact of cumulative depression along the HIV care continuum in women living with HIV during the era of universal antiretroviral treatment. JAIDS J Acquir Immune Defic Syndrom. 2019;82(3):225-33.

47. Dale SK, Pierre-Louis C, Bogart LM, O'Cleirigh C, Safren SA. Still I rise: the need for self-validation and self-care in the midst of adversities faced by Black women with HIV. Cultur Divers Ethnic Minor Psychol. 2018;24(1):15.
48. Crenshaw K. Demarginalizing the intersection of race and sex: a black feminist critique of antidiscrimination doctrine, feminist theory and antiracist politics. Univ Chicago Legal Forum. 1989; 140:25-42.

49. Bauer GR. Incorporating intersectionality theory into population health research methodology: challenges and the potential to advance health equity. Soc Sci Med. 2014;110:10-7.

50. Hancock A-M. When multiplication doesn't equal quick addition: examining intersectionality as a research paradigm. Perspect Politics. 2007;5(1):63-79.

51. Olson LC. On the margins of rhetoric: Audre Lorde transforming silence into language and action. Q J Speech. 1997;83(1):49-70.

52. Lorde A. Sister outsider: essays and speeches. Berkeley: Crossing Press; 2012.

53. Jones T, Norwood KJ. Aggressive encounters \& white fragility: deconstructing the trope of the angry black woman. Iowa L Rev. 2016;102:2017.

54. Rebeiro PF, Abraham AG, Horberg MA, Althoff KN, Yehia BR, Buchacz K, et al. Sex, race, and HIV risk disparities in discontinuity of HIV care after antiretroviral therapy initiation in the United States and Canada. AIDS Patient Care STDs. 2017;31(3):129-44.

55. Cohen MH, Cook JA, Grey D, Young M, Hanau LH, Tien P, et al. Medically eligible women who do not use HAART: the importance of abuse, drug use, and race. Am J Public Health. 2004;94(7):1147-51.

56. Murphy K, Hoover DR, Shi Q, Cohen M, Gandhi M, Golub ET, et al. Association of self-reported race with AIDS death in continuous HAART users in a cohort of HIV-infected women in the United States. AIDS (Lond, Engl). 2013;27(15):2413.

57. Pellowski JA, Price DM, Harrison AD, Tuthill EL, Myer L, Operario D, et al. A systematic review and meta-analysis of antiretroviral therapy (ART) adherence interventions for women living with HIV. AIDS Behav. 2019;23(8):1998-2013.

58. Bacon MC, von Wyl V, Alden C, Sharp G, Robison E, Hessol $\mathrm{N}$, et al. The Women's Interagency HIV Study: an observational cohort brings clinical sciences to the bench. Clin Diagn Lab Immunol. 2005;12(9):1013-9.

59. Cabral RR, Smith TB. Racial/ethnic matching of clients and therapists in mental health services: a meta-analytic review of preferences, perceptions, and outcomes. J Counsel Psychol. 2011;58(4):537.

60. de Haan AM, Boon AE, de Jong JT, Vermeiren RR. A review of mental health treatment dropout by ethnic minority youth. Transcult Psychiatry. 2018;55(1):3-30.

61. Brody LR, Jack DC, Weber KM, Cohen MH, Bassett SM, Clark $\mathrm{T}$, et al. Group treatment manual to promote positive affect and wellbeing in women living with HIV. Unpublished manuscript, Hektoen Institute of Medicine. 2018.

62. National Institute of Allergy and Infectious Diseases (NIAID). Women's Interagency HIV Study (WIHS) ClinicalTrials.gov2017. https://clinicaltrials.gov/ct2/show/NCT00000797

63. Adimora AA, Ramirez C, Benning L, Greenblatt RM, Kempf M-C, Tien PC, et al. Cohort profile: the women's interagency HIV study (WIHS). Int J Epidemiol. 2018;47:393-4.

64. Maxwell JA, Miller BA. Categorizing and connecting strategies in qualitative data analysis. In: Hesse-Biber SN, Leavy P, editors. Handbook of emergent methods. New York: Guilford Press; 2008. p. $461-77$.

65. Jack DC, Dill D. The Silencing the Self Scale: schemas of intimacy associated with depression in women. Psychol Women Q. 1992;16(1):97-106.

66. DeMarco RF, Lanier LR. The concept of "silencing the self" in low-income, aging, HIV-infected African American women: a 10-year community-based participatory program of research with results. J Assoc Nurses AIDS Care. 2014;25(2):112-22. 
67. Kayser K, Sormanti M. A follow-up study of women with cancer: their psychosocial well-being and close relationships. Soc Work Health Care. 2002;35(1-2):391-406.

68. Logie $\mathrm{CH}$, Wang Y, Lacombe-Duncan A, Wagner AC, Kaida A, Conway T, et al. HIV-related stigma, racial discrimination, and gender discrimination: pathways to physical and mental healthrelated quality of life among a national cohort of women living with HIV. Prev Med. 2018;107:36-44.

69. Earnshaw VA, Bogart LM, Dovidio JF, Williams DR. Stigma and racial/ethnic HIV disparities: moving toward resilience. Am Psychol. 2015;68:225-36.

70. Bassett SM, Cohn MA, Cotten P, Kwok I, Moskowitz JT. Feasibility and acceptability of an online positive affect intervention for those living with comorbid HIV depression. AIDS Behav. 2019;23:753-64.

71. Lefforge NL, Donohue B, Strada MJ. Improving session attendance in mental health and substance abuse settings: a review of controlled studies. Behav Ther. 2007;38(1):1-22.

72. Leddy AM, Sheira LA, Tamraz B, Sykes C, Kashuba AD, Wilson TE, et al. Food insecurity is associated with lower levels of antiretroviral drug concentrations in hair among a cohort of women living with HIV in the United States. Clin Infect Dis. 2019;71:1517-23.

73. Dale SK, Bogart LM, Wagner GJ, Galvan FH, Klein DJ. Medical mistrust is related to lower longitudinal medication adherence among African-American males with HIV. J. Health Psychol. 2016;21(7):1311-21.

74. Dalmida SG, Holstad MM, DiIorio C, Laderman G. The meaning and use of spirituality among African American women living with HIV/AIDS. West J Nurs Res. 2012;34(6):736-65.

75. Musgrave CF, Allen CE, Allen GJ. Spirituality and health for women of color. Am J Public Health. 2002;92(4):557-60.

76. Ironson GH, Stuetzle R, Fletcher MA. An increase in religiousness/spirituality occurs after HIV diagnosis and predicts slower disease progression over 4 years in people with HIV. J General Internal Med. 2006;21(S5):S62-8.

77. Chesney MA, Folkman S. Psychological impact of HIV disease and implications for intervention. Psychiatr Clin. 1994;17(1):163-82.

78. Brody LR, Carter AS. Children's emotional attributions to self versus other: an exploration of an assumption underlying projective techniques. J Consult Clin Psychol. 1982;50(5):665.

79. Fredrickson BL, Cohn MA, Coffey KA, Pek J, Finkel SM. Open hearts build lives: Positive emotions, induced through meditation, build consequential personal resources. J Pers Soc Psychol. 2008;95:1045-62.

80. Grossman P, Tiefenthaler-Gilmer U, Raysz A, Kesper U. Mindfulness training as an intervention for fibromyalgia: evidence of postintervention and 3-year follow-up benefits in well-being. Psychother Psychosom. 2007;76:226-33.

81. Creswell JD, Myers HF, Cole SW, Irwin MR. Mindfulness meditation training effects on CD4+ T lymphocytes in HIV-1 infected adults: a small randomized controlled trial. Brain Behav Immun. 2009;23(2):184-8.
82. Moen P, Dempster-McCain D, Williams RM. Successful aging: a life-course perspective on women's multiple roles and health. Am J Sociol. 1992;97(6):1612-38.

83. Galante J, Bekkers MJ, Mitchell C, Gallacher J. Loving-kindness meditation effects on well-being and altruism: a mixed-methods online RCT. Appl Psychol Health Well-Being. 2016;8(3):322-50.

84. Neff KD, Kirkpatrick KL, Rude SS. Self-compassion and adaptive psychological functioning. J Res Pers. 2007;41(1):139-54.

85. Neff KD. Self-compassion, self-esteem, and well-being. Soc Pers Psychol Compass. 2011;5(1):1-12.

86. Sirois FM, Kitner R, Hirsch JK. Self-compassion, affect, and health-promoting behaviors. Health Psychol. 2015;34(6):661.

87. Taylor SE, Collins RL, Skokan LA, Aspinwall LG. Maintaining positive illusions in the face of negative information: getting the facts without letting them get to you. J Soc Clin Psychol. 1989;8(2):114-29.

88. Taylor SE, Lerner JS, Sherman DK, Sage RM, McDowell NKL. Are self-enhancing cognitions associated with healthy or unhealthy biological profiles? J Personal Soc Psychol. 2003;85:605-15.

89. Ellard KK, Fairholme CP, Boisseau CL, Farchione TJ, Barlow DH. Unified protocol for the transdiagnostic treatment of emotional disorders: protocol development and initial outcome data. Cognitiv Behav Pract. 2010;17(1):88-101.

90. Barth J, Munder T, Gerger H, Nüesch E, Trelle S, Znoj H, et al. Comparative efficacy of seven psychotherapeutic interventions for patients with depression: a network meta-analysis. Focus. 2016;14(2):229-43.

91. Raiford JL, Wingood GM, DiClemente RJ. Correlates of consistent condom use among HIV-positive African American women. Women Health. 2007;46(2-3):41-58.

92. Pasco JA, Jacka FN, Williams LJ, Brennan SL, Leslie E, Berk M. Don't worry, be active: positive affect and habitual physical activity. Aust N Z J Psychiatry. 2011;45(12):1047-52.

93. Bopp CM, Phillips KD, Fulk LJ, Dudgeon WD, Sowell R, Hand GA. Physical activity and immunity in HIV-infected individuals. AIDS care. 2004;16(3):387-93.

94. Carver CS, Scheier MF. Origins and functions of positive and negative affect: a control process view. Psychol Rev. 1990;97:19-35.

95. Lent RW, Singley D, Sheu H-B, Gainor KA, Brenner BR, Treistman D, et al. Social cognitive predictors of domain and life satisfaction: exploring the theoretical precursors of subjective well-being. J Consult Clin Psychol. 2005;52:429-42.

96. Emmons RA. Abstract versus concrete goals: personal striving level, physical illness, and psychological well-being. J Pers Soc Psychol. 1992;62:292-300.

Publisher's Note Springer Nature remains neutral with regard to jurisdictional claims in published maps and institutional affiliations. 